\title{
MULHERES NEGRAS ESCRITORAS
}

\section{BLACK WOMEN WRITERS}

Florentina Souza

DOI: 10.11606/issn.1981-7169.crioula.2017.141317

RESUMO: O artigo se debruça sobre o importante papel da literatura produzida por mulheres negras como espaço de resistência ao epistemicídio que nega a elas o lugar de sujeitos de conhecimento. A expressão de força e atuação dessas muIheres é registrada de formas diversificadas, em livros, sites, blogs, no facebook, em revistas e jornais e também declamando nos saraus e slams.

ABSTRACT: The article focuses on the important role of the literature produced by black women as a space of resistance to epistemicide that denies them the place of subjects of knowledge. The expression of strength and performance of these women is recorded in a variety of ways, in books, websites, blogs, on facebook, in magazines and newspapers and also on declaiming performance in poetry parties and slams.

PALAVRAS-CHAVE: escritoras negras, resistência, poesia

KEYWORDS: black writers, resistance, poetry

1 Professora associada da Universidade Federal da Bahia. Atua no Programa de Pós-Graduação em Literatura e Cultura do ILUFBA e no Programa de Pós- Graduação em Estudos Étnicos e Africanos (CEAO-UFBA). Coordena o projeto EtniCidades: escritoras/es e intelectuais afro-latinos. Publicou, em 2005, o livro Afrodescendência em Cadernos Negros e Jornal do MNU. Em 2016, concluiu o estágio Pós-doutoral no Graduate Center da City University of New York. 
literatura brasileira e sua história canônica têm sido apresentadas como atividades produzidas por hoE mens; no entanto, estudos contemporâneos têm desencavado produções textuais de mulheres, algumas publicadas sob pseudônimo, em revistas e jornais e até mesmo em livros que terminaram se perdendo no decorrer dos tempos. Retratadas, descritas, com personalidades forjadas por homens e seus desejos, muitas mulheres tentaram escapar dedicando-se à escrita de textos religiosos e pedagógicos que eram acolhidos, desde que não fugissem aos padrões ideológicos estabelecidos pelos homens.

No século $X X$, umas das atividades intelectuais exercidas pelas mulheres foi a docência no então chamado ensino primário. Ali, ao lado de crianças (companhia mais que permitida, apreciada), muitas mulheres reproduziam conceitos e preconceitos aprendidos com seus pais, irmãos e maridos. Neste aprendizado, a literatura exerceu papel fundamental construindo personagens amadas ou odiadas, a depender de sua obediência ou não a padrões estabelecidos.

Exercendo papel secundário na vida social, elas muitas vezes esmeraram-se em descobrir brechas através das quais pudessem praticar alguma rebeldia e/ou exercer algum poder ${ }^{2}$. A escritora Gilka Machado pode ser apontada como um desses exemplos, nascida no Rio de Janeiro, nos finais do século XIX, 1893, tem como primeiro livro, Cristais Partidos, 1915. Em 1916, teve publicada sua conferência

2 Entre os primeiros momentos de atuação das mulheres na área das letras são apontados como marcos o livro Mulheres illustres do Brasil, de Inês Sabino, 1899, que dá início a uma série de antologias com textos e biografias de mulheres. As academias literárias femininas criadas no Ceará, Rio de Janeiro, Rio Grande do Sul, são outros exemplos de marcos dessa produção. 
"A Revelação dos Perfumes", e em 1917, Estados de Alma, Poesias, 1915/1917, Mulher Nua, em 1922, entre outros títulos. Além de militante pelo direito ao voto feminino e uma das fundadoras do Partido Político Feminino, é conhecida como uma das primeiras, senão a primeira poeta brasileira, a publicar poemas eróticos; por esta ousadia, recebeu críticas fortes de representantes do moralismo conservador tais como Humberto de Campos que atribui seus versos eróticos a sua "mentalidade "criola" e Afrânio Peixoto que a chama depreciativamente de mestiça, e mesmo Mário de Andrade teria criticado o que denominou de falta de moral em seus versos. Não obstante, recebeu vários prêmios de poesia no Brasil. Pouco citada nos compêndios de história da literatura, Gilka Machado teve seus poemas reeditados em 2017. Um dos poucos críticos a ressaltar a importância de Gilka para a literatura brasileira é Massaud Moisés que, no volume 2, História da literatura brasileira: simbolismo. São Paulo: Cultrix, 2001, pontua:

Gilka Machado ficou, e ficará, como exemplo, isolado em seu tempo, de corajosa transgressão das expectativas sociais com respeito à mulher. Feminista avant la lettre, rebelde, "selvagem", seu grito de liberdade exibe todas as características do pioneirismo, tanto mais digno de nota quanto mais se ergueu, e permaneceu longamente sonoro, num período em que rígidos preconceitos dominavam o convívio social (MOISÉS, 2001, p. 255).

Se a crítica do século XIX e XX se mostra intolerante com relação a escritoras brancas ou mestiças, a reação e indiferen- 
ça são mais acirradas no tocante às escritoras negras. Segundo alguns pesquisadores, entre eles, Maria Lúcia de Barros Mott, autoras como Rosa Maria Egipcíaca Vera Cruz, Teresa Margarida da Silva e Orta, Maria Firmina dos Reis, Antonieta de Barros, Auta de Souza, Gilka Machado e Maria Carolina de Jesus podem constituir um conjunto de primeiras mulheres negras que escreveram textos literários no Brasil. Os textos de algumas delas ainda carecem de estudos mais detalhados e alguns deles não são facilmente encontrados nas livrarias e bibliotecas, o que dificulta a realização de estudos e trabalhos sobre os mesmos.

\section{ResistênCIA AO EPISTEMICÍDIO}

Podemos afirmar que a escrita de mulheres negras, por muito tempo, foi ignorada pela crítica e entendida como uma textualidade sem valor literário. As escritoras negras e seus textos pareciam estar duas vezes fora de lugar. Ao assumirem a posição de sujeitos da escrita, elas rompem com o determinismo instaurado por séculos que aponta para as mesmas exclusivamente o lugar de serviçais e de objetos. Suas falas/ vozes não autorizadas foram, a priori, ignoradas, o que vem a constituir um epistemicídio, no dizer de Sueli Carneiro que, apropriando-se de Sousa Santos, utiliza o termo para caracterizar o modo como as tradições ocidentais negam às pessoas negras o lugar de sujeitos de conhecimento.

Para Boaventura Sousa Santos, o epistemicídio se constitui em um instrumento eficaz e duradouro de dominação étnica e racial que deslegitima as formas de conhecimento produzidas por grupos dominados e nega aos mesmos o papel de sujeitos do conhecimento. (apud Carneiro, 2005). Já Carneiro pontua: 
Para nós, porém, o epistemicídio é, para além da anulação e desqualificação do conhecimento dos povos subjugados, um processo persistente de produção da indigência cultural: pela negação ao acesso à educação, sobretudo de qualidade; pela produção da inferiorização intelectual; pelos diferentes mecanissmos de deslegitimação do negro como portador e produtor de conhecimento e de rebaixamento da capacidade cognitiva pela carência material elou pelo comprometimento da autoestima pelos processos de discriminação correntes no processo educativo. Isto porque não é possível desqualificar as formas de conhecimento dos povos dominados sem desqualificá-los também, individual e coletivamente, como sujeitos cognoscentes. E, ao fazê-lo, destitui-Ihe a razão, a condição para alcançar o conhecimento "legítimo" ou legitimado. Por isso o epistemicídio fere de morte a racionalidade do subjugado ou a sequestra, mutila a capacidade de aprender etc. (CARNEIRO, 2005, p.97).

Deste modo, toda atuação de homens e mulheres do continente africano e da diáspora africana é ignorada como parte do patrimônio cultural da humanidade. E mais, reiteradamente é apontada uma suposta inferioridade intelectual e criativa das pessoas negras que justificaria o desprezo às suas ponderações e expressões criativas (Idem).

Porém, as mulheres negras reagiram e reagem. Elas falaram, cantaram e escreveram. Insistiram em manter acesa a chama de sua criatividade e figuraram/figuram como exemplos para outras mulheres negras que contemporaneamente fazem uso da palavra em livros, sites, blogs, jornais e revistas, compartilhando suas leituras do mundo, do Brasil e das suas 
histórias. A estudiosa Ana Rita Santiago ${ }^{3}$, por exemplo, tem se dedicado a analisar textos de poéticos de mulheres negras, enfatizando marcas das construções de si e de seus diálogos com as tradições africanas e as estratégias para romper com as formas de invisibilização e silenciamento.

A poesia negra contemporânea pode ser lida como resultado da reação histórica de mulheres negras ao epistemicídio, ao silenciamento. Nos contatos com outras mulheres de grupos étnicos diversos, nos embates com os instrumentos da dominação escravista, nos mecanismos de preservação de aspectos religiosos, linguísticos, ou de conhecimentos variados, as mulheres utilizaram cantos e cânticos como arquivos da memória antes mesmo de acessarem a escrita ocidental.

No Brasil, os batuques, a capoeira, o samba, os congados, os maracatus, os candomblés, os cocos, entre outras expressões culturais, foram proibidos zelosamente pelos agentes policiais. Porém, como aponta Conceição Evaristo no poema "Meia lágrima" : "Da língua cortada,/ digo tudo, amasso o silêncio/ e no farfalhar do meio som/ solto o grito do grito do grito/ e encontro a fala anterior,/ aquela que emudecida,/ conservou a voz e os sentidos/ nos labirintos da lembrança" (2008, p. 50).

O sujeito poético, diante da violência da pedagogia colonial, é capaz de refazer sua fala, reconstituir sua cultura, superar os limites impostos e, através do silêncio, dos meios sons, os sentidos que garantem a sobrevivência de histórias e dos conhecimentos, consegue reagir ao epistemicídio secular.

Para Glissant, a empresa colonial forçou o contato entre culturas, propiciando a formação de culturas mistas, crioulizadas. Propositor de uma "poética da relação", ele afirma :

3 Refiro-me ao livro Vozes literárias de escritoras negras. Cruz das Almas, UFRB, 2012. 
no mundo atual temos plena consciência de que as culturas e as civilizações estão em contato constante umas com as outras. A poética da relação consistiria no abandono da pretensão de encontrar a verdade somente no círculo estreito de nossa subjetividade. $E$ penso que essa necessidade de superar a própria subjetividade - não com o objetivo de ir em busca de um sistema totalitário, mas sim de uma intersubjetividade do "Todo mundo"; "A função de toda literatura é a de participar desta busca" (2003, p. 158-9).

A produção de mulheres negras, inserida neste contexto, pode ser lida como uma estratégia de resistir ao epistemicídio; a quebra de fronteiras rígidas, as pequenas insurgências nas práticas cotidianas e artísticas, os movimentos sociais de rememoração de histórias impuseram às culturas dos países colonizados um colorido diversificado, um tom diferente; tom e cores que, na maioria dos casos, foram descritos como intervenções da cultura popular, à qual foi atribuído um significado hierarquizante e redutor. No entanto, por toda a diáspora, a cultura popular foi um dos espaços políticos de reconfiguração de identidades na diáspora; os jongos, os sambas apresentaram crônicas do cotidiano e versões da história que foram transmitidas de boca em boca.

Nos dois últimos séculos, a literatura escrita também tem se consolidado como um dos espaços de resistência e criatividade negras na diáspora. Concordo com Paul Gilroy quando ele afirma que a diáspora se constitui uma chave produtiva para pensarmos as culturas negras como revestidas de sentidos tecidos a partir da história da escravização e dispersão de 
africanos e seus descendentes por várias partes do mundo, ela possibilita trabalharmos em tensão com as chaves da similaridade e também as da diferenciação: "A diáspora fornece pistas e indícios valiosos para a elaboração de uma ecologia social de identidade e identificação cultural que nos leva para muito além do dualismo" (Gilroy 2007, p.154).

$\mathrm{Na}$ diáspora, as subjetividades destas mulheres marcadas por discriminações variadas, entre elas, as de base étnico-racial e de gênero, são forjadas na dupla relação com memórias pessoais e coletivas. Seus textos constituem uma modalidade poética no interior da literatura brasileira, uma linhagem caracterizada pela busca de uma poética/estética cultural que apresente especificidades das diferentes vidas das mulheres negras, pela tentativa de inserção na vida política, cultural e literária do país, para isto recorrem a várias formas de trabalho poético, desde a metalinguagem até o diálogo intertextual com a literatura canônica.

Se entendemos a poesia como dicção que estabelece ligações entre os seres humanos e suas histórias e culturas, entenderemos a produção de mulheres negras como criadora de uma poética da relação no sentido proposto por Glissant. Poética que fala de si, compartilha seus anseios e também abre-se para conhecer e falar a respeito dos anseios e histórias de outras pessoas.

Podemos afirmar que é gestada uma textualidade diversificada, como acontece com toda produção literária contemporânea no Brasil. De fato, constata-se um número crescente de textos de autoria de mulheres negras, algumas mais experientes outras mais jovens; o século XXI já apresenta quantidade expressiva de mulheres negras escrevendo em livros, 
sites, blogs, no Facebook, em revistas e jornais e também declamando nos saraus e slams. Tanto nos aspectos temáticos quanto formais, podemos observar a impossibilidade de uma caracterização que abarque a diversidade desta produção. As conquistas advindas dos avanços tecnológicos permitem que publicações circulem para além do suporte livro e favorecem que se efetivem diálogos entre leitores e autores. Se nas décadas de 1980 e 1990, as escritoras negras publicavam principalmente nos Cadernos $\mathrm{Negros}^{4}$, hoje, além do periódico, surgiram outras antologias e as autoras negras fazem dos blogs, individual ou coletivamente, o principal veículo de circulação de seus textos. A poesia escrita por mulheres negras na contemporaneidade aborda as experiências pessoais de construir identidades na interseccionalidade de categorias como étnico-raciais, de gênero, de classe, dentre outras. No entanto, não podemos dizer que a temática se restringe a falar da pessoalidade. O diálogo com as tradições africanas e diaspóricas comparece como tema frequente nesta poética. $\mathrm{Na}$ tentativa de apontar aspectos da pluralidade desta dicção, destacamos ainda a preocupação com a história, a religiosidade, a crítica social, o erótico.

A poesia desafia os cânones contemporâneos ao realçar demandas de grupos não hegemônicos. O quadro diversificado e múltiplo exige uma base epistemológica ampla, aberta, que seja capaz de abarcar conhecimentos e experiências que foram sistematicamente desqualificadas e apreciá-los segundo outra perspectiva poética e crítica.

4 Antologia de literatura negras que publica alternadamente poemas e contos de autores/as que se autodenominam negros/ afro-brasileiros desde 1978. 


\section{PoÉticas vozes de negras}

Cristiane Sobral, em texto publicado nos Cadernos $\mathrm{Ne}$ gros n. 37, arrisca uma definição do que ela denomina Poesia preta feminina: "poesia preta feminina/preciosa na monotonia da paisagem/ representa nossa diversidade/ entra na roda com muito axé" (CN 37, p. 51). Também eu acredito que a heterogeneidade de vozes consiste em uma das importantes marcas desta produção.

No presente texto não me deterei em apontar as diferenças entre literatura preta feminina, literatura negra feminina, literatura feminina negra ou literatura afro-brasileira produzida por mulheres. Não ignoro as nuances de sentido de cada expressão, porém uso-as indistintamente no texto, focalizando principalmente as vozes poéticas negras que falam de si e suas histórias através do texto poético.

Um dos temas frequentes na textualidade em foco é a descrição e também a relação com o corpo. A cor da pele e os sentidos que adquire através dos tempos têm sido tematizados por uma série de poetas negras enfatizando as suas várias possibilidades de representação. Seja para explicitar marcos históricos como os quilombos, seja como expressão do orgulho de pertencimento, seja para exaltar os links com países africanos. O fato é que cabelo, cor de pele, elasticidade e performatividade dos corpos negros têm gerado conotações diversas para os lugares ocupados pelos negros na diáspora. Stuart Hall, ao fazer "três comentários incompletos" a respeito da riqueza das tradições diaspóricas, no texto "Que 'negro' é esse na cultura negra”, afirma: “... pensem como essas cultu- 
ras têm usado o corpo como se ele fosse, e muitas vezes foi, o único capital cultural que tínhamos. Temos trabalhado em nós mesmo como em telas de representação" (2003, p.342). Nota-se que as mulheres negras investem em um trabalho de ressignificação dos seus corpos e do corpo negro em geral.

O corpo negro é vilipendiado pelo racismo e o sexismo impõe ao corpo da mulher uma dupla carga de opressão; nem mesmo os avanços contemporâneos têm sido suficientes para retirar as mulheres negras de representações que as aprisionam a papéis que enfatizam a objetivação. Poetas negras buscam representar seus corpos fora dos enquadramentos racistas e sexistas, destacando o seu papel histórico na tessitura das relações familiares, sociais, econômicas e culturais. "A noite não adormece/ nos olhos das mulheres, /a lua fêmea, semelhante nossa, / em vigília atenta vigia/ a nossa memória" (EVARISTO, 2008, p. 21)

O sujeito poético feminino ressalta o papel de guardiã atenta da memória; daquelas memórias que cortaram o Atlântico: cantos, danças, contos, tradições culinárias, medicinais e religiosas. Resistindo e lutando, às vezes silenciosamente, outras nem tanto, as mulheres como, por exemplo, Luiza Mahin, Maria Firmina dos Reis, artistas, tantas professoras primárias, por este vasto Brasil, fizeram de seus corpos instrumentos de intervenção e atuação na vida social brasileira como a ratificar os versos de Evaristo: "A noite não adormecerá/ Jamais nos olhos das fêmeas,/ pois do nosso sangue-mulher/ de nosso líquido lembradiço/ em cada gota que jorra/ um fio invisível e tônico/ pacientemente cose a rede/ de nossa milenar resistência" ( 2008, p.21). A resistência tecida nos fios do cotidiano de carências e nos desafios às mesmas. 
A estudiosa Ana Lucia Souza, ao falar de práticas criativas urbanas de autoria de jovens negros, destaca tais produções como expressões de letramentos de reexistência e explica: os letramentos de reexistência mostram-se singulares, pois, ao capturarem a complexidade social e histórica que envolve as práticas cotidianas de uso da linguagem, contribuem para a desestabilização do que pode ser considerado como discursos já cristalizados em que as práticas validadas sociais de uso da língua são apenas as ensinadas e aprendidas na escola formal" (2009, p. 24).

Ora, o sistema educacional e a tradição literária definem não somente quem está autorizado a produzir literatura, mas também sobre o que deve o autor escrever. Os textos em foco investem contra tais definições e constituem sujeitos poéticos que, partícipes da "milenar resistência", apresentam seus anseios e seus corpos e reescrevem histórias e sentimentos e compartilham as suas vivências com mulheres e homens.

Cristiane Sobral, também autora de vários livros de poemas, elabora, na maioria dos textos, uma poética que busca explicitamente uma interlocução com diversos leitores, enfatiza a resistência como uma das características do sujeito poético feminino e, principalmente, a disposição deste sujeito para quebrar paradigmas estabelecidos e contestar essencializações. Em livro intitulado Só por hoje vou deixar o meu cabelo em paz, a poeta faz exatamente o contrário do que pode sugerir o título - Em muitos poemas se reporta ao corpo negro com foco no cabelo. Aspecto corpóreo dos mais utilizados pelos discursos representacionais, como afirma Nilma Gomes, "o corpo é uma linguagem, e a cultura escolheu algumas de suas partes 
como principais veículos de comunicação. O cabelo é uma delas" (2006, p. 260). A poeta faz do cabelo um metonímia para abordar representações das identidades negras, principalmente das mulheres negras, estabelecendo uma relação entre exterioridade (cabelo) e interioridade (subjetividade e identidade negras); no poema "Espere o inesperado", a ordem dos lisos, da branquitude e do sexismo é chacoalhada pelo pente tridente que além de sua função para os cabelos, evoca Exu, o criador de ordens diferentes, o dono das encruzilhadas- o que traz novas ordens, ampliando, assim, noções e conceitos de histórias e memórias: "Diferente, o meu pente/quase um tridente/ transforma ordem/ Sem fazer desordem" (idem, p 21).

Em outro momento, Cristiane Sobral constrói um eu poético que se define como agente e sublinha intensamente a identidade deste sujeito: pássaro preto, águia negra sempre detentora do poder de recriar-se :

Forjo uma pele nova a cada momento. Sou pássaro preto/ Estendo as minhas asas/ Coloco fogo na dor/ Espalho as cinzas negras pelo meu corpo/ Forjo uma pele nova a cada momento/ Jogo as cinzas ao vento/ e voo/ Águia negra/ A ressuscitar diante de qualquer tempestade (2014, p.36).

Já a poeta Lívia Natália, partícipe da milenar resistência, investe em apresentar o corpo da mulher negra a partir de uma estratégia que brinca com os sentidos dicionarizados de "Relicário"; no poema homônimo mistura devoção, memória, relíquias. Assim representado, o corpo do sujeito poético tran- 
sita como agente entre passado, presente e futuro, vida privada e pública, o esperado e o inusitado:

périplo de rotas insondáveis. Meu corpo é das delicadezas, /enxovais completos,/ toalhas brocadas/ iniciais maiúsculas no tapete do chão.// Meu corpo é um antiquário-/ memória fina do inútil, seara do translúcido.// Meu corpo é das delicadezas/ asas de transparente voar./ périplo de rotas insondáveis. (2016, p.51).

O sujeito poético feminino apodera-se dos sistemas de representação para se auto definir, escolhendo os vínculos que lhe permitem falar de si, produzir identidades fora de modelos produzidos por olhares estreitos.

Além de agentes no sistema representacional, as poetas negras se colocam como fazendo parte de um universo assumidamente heterogêneo, que recusa identidades unas ou fixas; assim, ao falar de mulher negra, Mel Adun no poema "PRETAs, NEGAs, NEGUINHAs", desde o título, anuncia a recusa à homogeneização representacional. O eu poético utiliza o plural para tensionar e romper o enquadramento em duas ou três imagens fixas que permeiam os discursos literários hegemônicos. As mulheres negras no poema evidenciam a diversidade muitas vezes escondida na expressão "Mulher negra" e finaliza o poema: "Somos negras de todos os tons/ as recatadas, as exibidas/ as fartas, as na medida/ as de parar o trânsito e também as desenxabidas" ( Antologia da poesia negro-brasileira erótica , 2015,p.35). 
A poeta Jenyffer Nascimento também desafia, no poema "Antítese", a ditadura de definições controladoras do corpo, pensamento e desejos da mulher: corpo, atitude, voz, comportamentos e decisões são ações executadas pelo sujeito feminino que sempre está rompendo com as expectativas do outro que deseja moldá-lo.

Pediram um corpo escultural

Eu não tinha.

Quiseram uma mulher ignorante

Eu já tinha lido o suficiente para me proteger

Sugeriram que eu não opinasse em assuntos de homem Eu nunca consenti em calar.

Submeteram meu corpo e meu psicológico à violência Eu me juntei a outras como eu para superar.

Compraram vaidades para que eu me adequasse Eu envaideci aprendendo palavras de ordem na luta.

Exigiram fidelidade e submissão

Eu rompi por amor próprio.

Cagaram mil e uma regras de conduta Eu mandei pra puta que pariu E sorri, feliz

(NASCIMENTO, In blogueirasnegras.org) 
Empoderadas, mulheres negras investem em transformar as imagens que lhes foram impingidas, desejam transformar os modos como são vistas e para isto empreender uma luta, com vistas a fazer intervenções no sistema de representação redutor.

A poetisa Jovina S., no poema "Herança de mãe", seleciona os elementos que vão caracterizar a reexistência de mulher negra. Traça uma genealogia de escrita e de experiência com a vida em que a vontade, a criatividade do sujeito poético são marcas decisivas, em outras palavras, representa o sujeito poético feminino e negro como agente, sujeito das ações e das representações:

Pego o papel e sou deusa. Invento o mundo,

Nem sempre escrevo o que ele me dá,

Gosto de chover na estiagem para fazer

Plantações, dançar na colheita dos frutos doces.

Crio outros mundos para renegar o que esse Mundo nos traz, fazer desvios.

Aprendi com mãe que vencia muros todo dia, Ela tinha essa força.

Trazia para essa terra de racismo perverso

Outros caminhos, assim que amanhecia.

Eu fiquei com sua missão de pular paredes

E construir caminhos (CN 37, p.132)

Como deusa, o sujeito demonstra sua capacidade de gerenciar sua vida: inventa, cria, dança, faz desvios e por fim 
intervém no mundo que a deseja imobilizar; pula paredes e constrói caminhos. Transmitida de mãe para filha, a re-escritura da existência aparece como uma missão, um traço hereditário reconfigurado no presente.

A poeta Miriam Alves no Poema " Mulher em luta" enfatiza a escrita da mulher negra como resultado de processo de organização de emoções e também de um trabalho de escavação da palavra. Uma poesia que, a partir dos resíduos, das mortes e da atuação sobre as palavras, torna os momentos de luto potência criativa:

enluto-me e o poema sai assim

meio mágoa

meio lágrima

meio torto

toda lança

enluto-me por aquelas vinda no arrastão atlântico

enluto-me ao ver dilacerar pele, corpo e mente

(...)

eu mulher em toques no teclado

faço das luzes da tela meu alento

alimento em palavras

o meu desejo pleno de ser

e vou tiquetaqueando retirando das vogais sons

palavras e imagens

tamborilando mensagem vou

(CN 33, p. 122) 
A escrita em foco também se detém em diálogos com a tradição canônica e também com uma tradição de escrita negra. A intertextualidade e a metalinguagem aparecem como demonstração do desejo de diálogo crítico, a exemplo do texto de Conceição Evaristo no poema "Carolina na hora da estrela"

No meio da noite

Carolina corta a hora da estrela.

Nos laços de sua família um nó

- a fome.

José Carlos masca chicletes.

No aniversário, Vera Eunice desiste

do par de sapatos,

quer um par de óculos escuros.

João José na via-crucis do corpo,

um sopro de vida no instante- quase

a extinguir seus jovens dias.

E lá se vai Carolina

com os olhos fundos,

macabeando todas as dores do mundo...

na hora da estrela, Clarice nem sabe

que uma mulher cata letras e escreve

"De dia tenho sono e de noite poesia."

(EVARISTO, 2017, p. 96.)

A conhecida poeta negra forja um diálogo intertextual com duas conhecidas escritoras: Maria Carolina de Jesus e Clarice Lispector, inseridas em cânones diferentes da literatura brasi- 
leira. A poetisa mescla aspectos da biografia de Carolina com títulos e personagens da obra de Clarice, criando um jogo em que as dessemelhanças parecem ser realçadas.

Carolina aparece em atuação na busca pelo alimento dos filhos, " macabeando todas as dores do mundo" que atingem uma mulher negra, catadeira de lixo, moradora de favela, escritora que, antes de Macabéa, sonhava ser estrela. Evidenciando conhecer a obra das duas, Conceição Evaristo funde metalinguagem e intertextualidade em texto que faz pensar sobre complexidades da literatura e da crítica no Brasil.

As intervenções poéticas das mulheres negras citadas e de tantas outras como Esmeralda Ribeiro, Rita Santana, Elizandra Souza, Cidinha da Silva, e outras e outras, trazem para a cena reflexões, teorias, memórias das dores, alegrias, vitórias e empoderamento de mulheres que fazem de seus sentimentos, de suas histórias, de seus corpos negros, palco para exibição de dramas - os pessoais e também outros -, gestados em histórias e memórias coletivas e, principalmente, no desejo de validação de seus textos e saberes. 


\section{REFERÊNCIAS BIBLIOGRÁFICAS}

CADERNOS NEGROS. São Paulo: Quilombhoje, 2010, vol. 33.

CARNEIRO, Sueli. A Construção do Outro como Não-Ser como fundamento do Ser. Feusp, 2005. (Tese de doutorado).

EVARISTO, Conceição. Poemas da recordação e outros movimentos. Belo Horizonte: Nandyala, (coleção Vozes da Diáspora Negra, Volume 1), 2008.

EVARISTO, Conceição. Poemas da recordação e outros movimentos. Rio de Janeiro: Malê, 2017.

GILROY, Paul. Entre campos: nações, culturas e o fascínio da raça. São Paulo: Annablume, 2007.

GLISSANT, Édouard. Introdução a uma poética da diversidade. Juiz de Fora: UFJF, 2005. Trad. Enilce Albergaria Rocha.

HALL, Stuart. Que negro é esse na cultura popular negra. IN. Da diáspora: Identidade e mediações culturais. Brasília: UNESCO; Belo Horizonte, UFMG, 2003, p. 335 a 349.

MOISÉS, Massaud. História da literatura brasileira: simbolismo, vol 2. São Paulo: Cultrix, 2001. 
SOUZA, Ana Lúcia Silva. Letramentos de Reexistência: culturas e identidades no movimento hip-hop . Campinas, SP: [s.n.], 2009. Tese de doutorado.

SOUZA, Florentina da Silva. Facetas das discussões de gênero no século 20. In $O$ futuro do presente: arquivo, gênero e discurso. Belo Horizonte: UFMG, 2012, p.181-200.

Submissão 04/12/2017

Aceite: 04/12/2017 